Ravi Passos [UNB], Mônica Moura [UAM]

\title{
Design da informação na hipermídia
}

Information design in the hypermedia

\begin{abstract}
design, informação, hipermídia
Este trabalho tem por objetivo discutir o design da informação e sua relação com a hipermídia. Partindo da caracterização do design da informação e de termos tangentes, pretende-se confrontar informações que elucidem as atividades relativas a esta área de atuação, suas peculiaridades e os conceitos para sua utilização. Pretende-se ainda levantar as características hipermidiáticas que trazem a relevância da organização da informação, partindo-se para o modo como se dá tal tarefa projetiva, levando a uma melhor compreensão sobre o tema. Como resultado, temos a apresentação e caracterização da área disciplinar responsável pelo tratamento de informações em mídias digitais interativas.
\end{abstract}

design, information, hypermedia

This work aims at discussing information design and its relation to hypermedia. Starting from the characterization of information design and similar terms, we confront herein information that elucidate activities related to that field, as well as its peculiarities and concepts involved in its utilization. This work also intends to point out hypermediatic characteristics that make information organization relevant, and to discuss the way in which such projective task is performed. As a result, we present and characterize the field which is responsible for treating information in interactive digital media.

\section{Introdução}

Incentivada pelo desenvolvimento das tecnologias de informação e comunicação - TICs, a sociedade contemporânea tem passado por grandes transformações relativas à quantidade, ao fluxo e ao modo de acesso à informação. Embora nem sempre a relação entre estrutura e forma do conteúdo exista de maneira adequada, o mundo funciona à base de informação, percepção e síntese de informação.

O livre e rápido fluxo de informação tem a capacidade de diluição de fronteiras territoriais, tendendo a homogeneizar as diferenças culturais, uma vez que diversos locais têm acesso às mesmas informações. A conexão entre computadores, assim como os avanços da tecnologia, torna possível o processamento de informações em larga escala e de forma instantânea, tanto em sua produção quanto em sua distribuição e em seu consumo (WURMAN, 1991). A Internet tem sido um dos principais veículos dessas transformações, na medida em que grande parte das tecnologias se utiliza dela como meio de propagação de dados.

Como instrumento essencial de acesso à rede, tem-se a hipermídia sendo amplamente utilizada na recuperação, transformação e produção de informações. A relevância da hipermídia dá-se devido às suas características elementares, tais como alta capacidade interativa, fluxo contínuo de diálogo com as informações, elaboração visual e grande capacidade de armazenagem de hiperdocumentos.

Uma hipermídia pode ser considerada como um sistema digital interativo composto por diferentes tipos de mídias e disposto de forma hipertextual em um determinado artefato ${ }^{3}$, seja ele um CD-ROM, um website ou um terminal de auto-atendimento. Para esclarecer melhor esta definição, faz-se necessário um breve apanhado conceitual, em busca de suas bases.

Para Lévy (1993, p. 33),

' um hipertexto é um conjunto de nós ligados por conexões. Os nós podem ser palavras, páginas, imagens, gráficos ou partes de gráficos, seqüências sonoras, documentos complexos que podem eles mesmos ser hipertextos. Os itens de informação não são ligados linearmente, como em uma corda com nós, mas cada um deles, ou a maioria, estende suas conexões em estrela, de modo reticular. Navegar em um hipertexto significa portanto desenhar um percurso em uma rede que pode ser tão complicado quanto possível. Porque cada nó pode, por sua vez, conter uma rede inteira.'

3 Artefatos são objetos que possibilitam ações efetivas (BONSIEPE,1997). 


\section{Infodesıgn}

Em um esclarecimento complementar, Costa (1999, p. 254) coloca que um hipertexto é 'uma forma não linear de se apresentar e consultar informações' vinculando informações e criando uma rede de associações por meio de ligações. O termo hipertexto, segundo Ulbricht (2006, p. 20), faz referência a 'um documento imaterial, e esta imaterialidade the confere a propriedade de ambigüidade', pela possibilidade de ser compartilhado por várias pessoas, cada qual adotando seu próprio percurso e sua própria leitura.

Um sistema interativo pode ser decomposto em núcleo funcional e interface com o usuário. $O$ núcleo funcional é formado por programas aplicativos, algoritmos e base de dados. A interface com o usuário compreende as apresentações de informações, de dados, de controles e de comandos do sistema regido pelo núcleo funcional (CYBIS, 2003). A representação deste sistema pode ser vista na figura 1 , a seguir.

Figura 1: Interação de um sistema: Núcleo funcional > Interface com usuário > Usuário

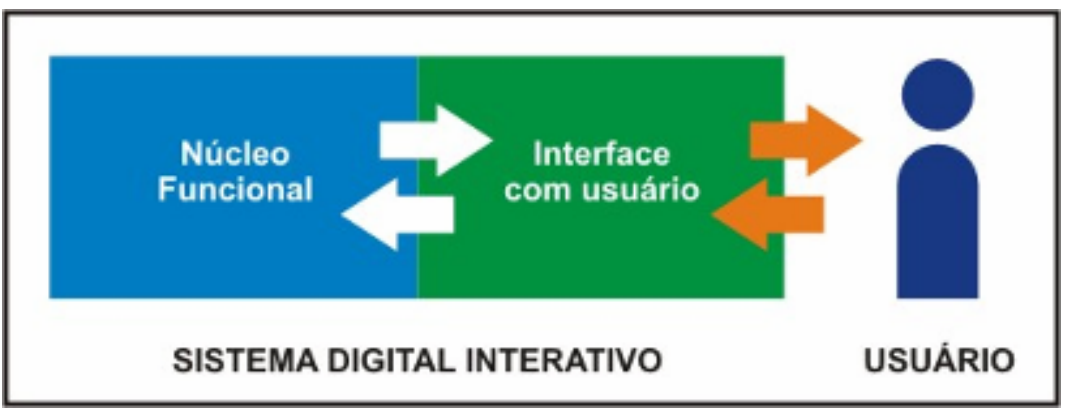

É a interface com o usuário que torna possível a comunicação entre as partes sem que haja a necessidade que o usuário conheça linguagens de programação. É a interface que solicita e recepciona as entradas de dados, de controles e de comandos. Finalmente, ela controla o diálogo entre as apresentações e as entradas. Uma interface tanto define as estratégias para a realização da tarefa, como conduz, orienta, recepciona, alerta, ajuda e responde ao usuário durante as interações (CYBIS, 2003).

As características apontadas acima sobre hipermídias proporcionam uma forma bastante amigável e adequada para a navegação, uma vez que são cognitivamente adequadas e aceitas pelo usuário destes artefatos. Porém, não basta que existam avançados meios de acesso às informações nem que a forma de comunicação e interação seja adequada ao raciocínio humano. É necessário que a própria informação esteja organizada e estruturada de maneira a ser assimilada pelo leitor, pois 'a compreensão de uma estrutura e sua organização de informação permite a compreensão de valor e significado de seu conteúdo' (WURMAN, 1991, p. 72).

O design, em seu papel interdisciplinar focado nas necessidades do usuário, assume uma função essencial neste contexto de organização e estruturação informacional. Ele agrega em si os conhecimentos necessários à estruturação funcional e à fundamentação de linguagem e comunicação visual. Assim sendo, é capacitado para a ação projetiva dos artefatos digitais interativos voltados à maximização da capacidade tecnológica e humana, na atividade de leitura do mundo virtual que se dá por meio de uma interface que possibilite a comunicação efetiva entre a informação e o interator.

É importante salientar que os clássicos princípios e paradigmas estabelecidos para o design gráfico e de produto não bastam para suprir as demandas das mídias digitais e interativas, pois estes princípios e paradigmas foram estipulados com o pensamento voltado para planos materiais bi e tridimensionais. Assim sendo, faz-se necessário 'o estabelecimento de relações entre a cultura, a linguagem, a interdisciplinaridade, a transdisciplinaridade e a aplicação do design da informação para o fazer projetual perante as novas mídias' (MOURA, 2003b, p.3).

\section{0 design da informação como colaborador nas demandas projetuais}

Antes da abordagem teórica, faz-se necessária uma consideração sobre a nomenclatura "design da informação", que será amplamente utilizada no decorrer do texto. Com apoio na argumentação de Bonsiepe (1997), de que a arquitetura tem sua relação significativa com a articulação do espaço, e o design, no âmbito visual, tem sua relação com a estruturação de informações e interpretação de mensagens, podemos deduzir que a utilização da nomenclatura arquitetura de informação, amplamente empregada para designar a área de conhecimento responsável pelo tratamento estrutural da informação, de certa forma pode ser insuficiente quando relacionada ao projeto de hipermídia, principalmente porque a simples ordenação de conteúdo não 
garante a sua compreensão.

Rosenfeld (2002, p. 19) utiliza o termo arquitetura em sua teoria a respeito do tema, porém, o sentido empregado por ele abrange muito mais que a articulação de espaço, pois emprega conceitos relacionados ao design, como mostrado nos apontamentos a seguir ${ }^{4}$ :

a. A combinação entre organização, rotulação e navegação esquemática dentro um sistema de informação.

b. O projeto estrutural de um espaço informacional visando facilitar a conclusão da tarefa de acesso ao conteúdo de forma intuitiva.

c. A arte e ciência de estruturação e classificação de websites e intranets de forma a ajudar as pessoas a encontrar e gerenciar informações.

d. Uma disciplina e uma comunidade emergentes da prática focada em princípios de design e arquitetura para o cenário digital.

Após a colocação de suas definições, o autor ainda alerta que as definições são amplas, o que, por inferência, permite uma consideração menos rígida ou conclusiva.

A necessidade de transpor a estruturação e aglutinação da informação, visando o entendimento conceitual entre elementos, seus significados e relações, torna mais pertinente a este trabalho o uso da nomenclatura "design da informação", que contempla não somente as questões relativas à organização dos dados e de suas rotas de acesso, tarefa marcante na arquitetura, mas também as relações entre conteúdo, comunicação visual e linguagem. No contexto corrente, o design da informação circunscreve a arquitetura de informação no papel de tratamento da informação, pois contempla a atividade projetiva com maior abrangência $e$ detalhamento, propiciando proximidade em determinadas etapas e requisitos da elaboração de interface, tornando-a mais adequada e eficaz.

O design da informação pode ir além da interpretação ou modificação visual e é anterior à simples estruturação de dados. Além de tradutor de informações, ele tem uma função autoral (BONSIEPE, 1997), pois faz a transposição expressivo-formal das informações e de suas relações.

Segund o Horn ${ }^{5}$ (1999, p.15), o design da informação é definido como a arte e a ciência de preparação da informação, possibilitando seu uso pelo homem de maneira eficiente e efetiva, sendo seus principais objetivos:

a. Desenvolver documentos compreensíveis, de recuperação fácil e ágil e capazes de serem traduzidos em ações efetivas;

b. Projetar interações com equipamentos de forma fácil, natural e o mais agradável possível. Isso implica na resolução de problemas no design de interface homemcomp utador;

c. Possibilitar que as pessoas encontrem seus caminhos em espaços tridimensionais com facilidade e conforto, seja no plano material ou virtual.

O design da informação trata o conteúdo de sistemas complexos de informação no âmbito de selecionar e estruturar a organização das informações. Ele é responsável por delinear a forma na qual o usuário encontra as informações, realiza sua leitura, estabelece a relação entre seus elementos, interage com a interface e compreende esta experiência. Em alguns casos, nos quais o trabalho de interação é mais elaborado, a experiência da navegação pode remeter a relações de sinestesia ou imersão em ambientes hipermidiáticos. Essas relações são estabelecidas por fundamentos de linguagens e hardwares que maximizam a utilização das mídias.

Diante desses apontamentos pode-se caracterizar o design da informação para hipermídia com maior amplitude que um projeto de estrutura e acesso. Nesta relação, a nomenclatura está ligada não somente a rotas de entrada, saída e aglutinação de dados, mas sim à modificação do conteúdo em informações assimiláveis e compreensíveis, possibilitando sua posterior transformação em conhecimento e experiência.

Os elementos que compõem as interfaces de um dado artefato hipermidiático devem ser tratados como agentes facilitadores na assimilação e na compreensão da informação, e também como colaboradores no processo de aprendizado. A estrutura de uma interface deve passar despercebida ao usuário, para que só o conteúdo apareça (RADFAHRER, 2003). 


\section{Infodesıgn}

\section{Características da hipermídia}

Um projeto gráfico ${ }^{6}$ de um produto digital envolve mais elementos que seu equivalente em mídia impressa (RADFAHRER, 2003). As interfaces digitais são constituídas por elementos textuais, gráficos, sonoros (como janelas, ícones, menus, teclas etc.), estáticos e dinâmicos, relacionados entre si e com o seu conteúdo informacional. Estas interfaces são compreendidas como instrumentos metafóricos de realidades com a qual o usuário está familiarizado. Porém, estes elementos não "representam" uma realidade e sim "constituem" uma realidade própria, na medida em que este usuário vivencia um espaço de ação (BONSIEPE, 1997, p. 41).

A hipermídia, como sistema digital interativo, tem sua concepção condicionada ao design da informação, pois é detentora de uma série de características que amplificam a necessidade projetiva. Tais características, como grande interatividade, fluxo contínuo de informação, convergência midiática, ligações hipertextuais, alimentação constante de conteúdo e adaptação continuada de tecnologia, tornam o projeto de hipermídia bastante complexo.

Em situação real de uso, tem-se a complexidade característica da hipermídia aliada a um volume crescente de informação produzida e disponibilizada na rede. O cenário obtido pela aliança entre complexidade projetiva e volume informacional remete à necessidade do estudo de como se dará a interação entre usuário e interface de forma mais adequada para que haja uma comunicação efetiva que possibilite a transformação da informação em conhecimento ou simplesmente para que uma dada informação cumpra seu papel junto ao usuário.

Combinando canais perceptivos (linguagem, imagem e som), a hipermídia permite a interação em forma de navegação entre nós semânticos. Sua diferenciação entre meios audiovisuais está em sua organização em rede e na possibilidade de navegação do espaço informacional (BONSIEPE, 1997). Percebe-se então que o projeto de hipermídia detém uma grande quantidade de informação estruturada de forma hipertextual, com seus respectivos hiperdocumentos. Esta estrutura possibilita a existência de muitas informações associadas, em processo de constante atualização e alimentação de conteúdo que estruturam interfaces e suas possibilidades de interação (MOURA, 2003a).

\section{Como se dá o design da informação na hipermídia}

As características das hipermídias relativas a estruturação hipertextual, apresentação e acesso a conteúdo, diversidade de possibilidades de navegação e interação, são fatores que aumentam consideravelmente a importância do design da informação em sua concepção. Isto se dá uma vez que a quantidade de informação está associada às várias possibilidades de mídias, linguagens (imagéticas, sonoras e textuais) e relações entre seus elementos compositivos, além das condições inerentes ao processo de interação entre usuário e interface e entre o sistema interativo e a rede. Consecutivamente, isso reflete na sobrecarga cognitivo-informacional à qual o usuário é submetido, daí a necessidade de maior atenção com o projeto da interface e de seu conteúdo, visando à facilitação do acesso às informações e assimilação de suas características conceituais.

Como já afirmado, o design da informação 'enfoca a tarefa da comunicação na perspectiva de organizar a informação' e está relacionado com a estruturação, a organização e a acessibilidade das informações. Ele colabora no reconhecimento e na compreensão de fatos e conceitos pela seleção, arranjo, hierarquização e combinação de distinções visuais. Visando a facilitação de ações efetivas, o design da informação abre novas possibilidades para os usuários, e sendo consistentes facilita o aprendizado de uso da interface e de seu conteúdo (BONSIEPE, 1997, p. 146).

\subsection{Agrupamento de informação}

O design da informação 'envolve a organização das informações e o planejamento da maneira como os usuários as encontrarão, o que caracteriza um projeto de estrutura e acesso' (MOURA 2003a, p. 252). Assim sendo, o tratamento da informação pode se dar pelo processo de agrupamento das informações semelhantes, e seus acessos devem ser configurados de acordo com as características almejadas pelos usuários e suas forma de navegação. A usabilidade ${ }^{7}$ também traz sua contribuição na medida em que seus princípios tratam da facilitação, agradabilidade e eficiência de navegação.

6 Respeita-se a nomenclatura "projeto gráfico" utilizada por Radfahrer, porém, compreende-se que é mais indicada, por sua abrangência, a utilização da nomenclatura "projeto visual e interativo" ou "design digital".

7 'Usabilidade é a capacidade que um sistema interativo oferece ao seu usuário, em um determinado contexto de operação, para a realização de tarefas, de maneira eficaz, eficiente e agradável' (ISO 9241 apud CYBIS, 2003). 
Segundo Wurman (1991), as formas de se organizar as informações são finitas e estão em cinco grupos de possibilidades (Categoria, Tempo, Localização, Alfabeto e Seqüência), conforme explicado abaixo:

- Categoria: agrupamento de bens diversos, genéricos, geralmente de importância similar.

- Tempo: agrupamento por localização ou referencial temporal, seja em ordem cronológica ou periódica.

- Localização: agrupamento por localização, referencial geográfico ou geométrico.

- Alfabeto: agrupamento por ordem alfabética.

- Seqüência: agrupamento relativo à atribuição de peso ou valor de alguma informação. Tem caráter hierárquico do maior ao menor ou vice-versa. informação:

Moura (2003a, p. 253) reúne em três fases a estruturação dos elementos do design da

- Inventário das informações: levantamento de todos os elementos que serão incluídos no projeto de hipermídia.

- Organização das informações: agrupamento das informações por critérios de relação entre elas.

- Formato de estrutura geral: construção de diagrama ou fluxograma indicando a disposição das informações e suas relações.

Em um processo global correlato, acrescido de etapas metodológicas de projeto, Radfahrer (2003, p. 124), propõe as seguintes etapas:

- Identificação do problema;

- Classificação de suas particularidades;

- Levantamento de dados;

- Definição de estruturas hierárquicas (neste ponto utilizam-se as regras de Richard Soul Wurman);

- Aglutinação de temas relevantes;

- Estudo de navegabilidade e

- Pontos de interatividade.

Com o detalhamento da aglutinação da informação e suas rotas de acesso, define-se um mapa estrutural do sistema que mostre os percursos que o usuário terá para percorrer o sistema, de acordo com suas necessidades e objetivos.

\subsection{Apresentação visual e estrutural do projeto}

A comunicação visual e estrutural do conteúdo selecionado e já agrupado, que antecede a execução de um projeto de hipermídia, se dá por meio de mapas de acesso, também chamados de diagramas e fluxogramas, conforme figura 2. 'Mapas são os meios metafóricos através dos quais podemos entender a informação que vem de fontes exteriores e agir sobre ela' (WURMAN, 1991, p. 281). Assim como os mapas, os diagramas têm a função específica de ajudar os indivíduos a processar a informação, permitindo o entendimento conclusivo, em meio a uma grande quantidade de informações.

A proposta de um diagrama ou de um fluxograma é comunicar a estrutura de um sistema digital, como um mapa, fornecendo a orientação para o desenvolvimento de um projeto. Ele 'representa o relacionamento entre os links, as seções e as interfaces, criando um sentido de espaço e sugerindo o sistema de navegação' (MOURA, 2003a, p. 254). 


\section{Infodesıgn}

Figura 2: Exemplo de possível mapa de estrutura e acesso do site do estúdio 2ADVANCED.

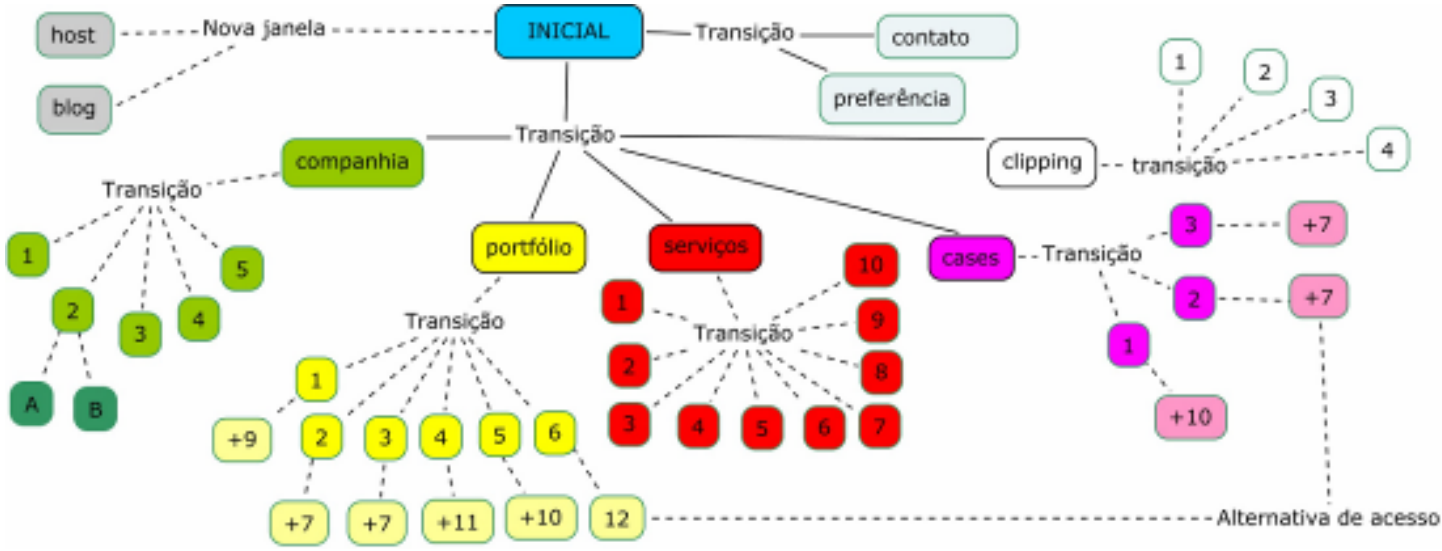

Técnica e conceitualmente, o mapa indica as diversas possibilidades de conexão entre hiperdocumentos de um mesmo sistema. Ele deve promover a indicação das mais variadas formas de acesso ao conteúdo da hipermídia, visando à navegação contínua em que o usuário não precisa retornar a nenhum local sem que seja de sua vontade. Serve ainda para apontar o agrupamento entre elementos e seções, colaborando no planejamento de sua implementação.

\subsection{Organização de elementos na interface}

Segundo Radfahrer (2003), uma das melhores maneiras de se organizar os elementos de uma interface digital é usar grades de alinhamentos (também chamadas de grids ou malhas). Com a função de ordenar a informação, a malha padroniza a interface e ajuda o usuário a achar o que procura, dividindo os espaços dando maior consistência ao layout.

No contexto do projeto de interfaces de hipermídias, utiliza-se o termo wireframe ${ }^{8}$ com papel similar ao da malha: indicando o local de conteúdo em uma interface e suas relações. Geralmente sua construção se dá pela divisão da área útil de uma interface em linhas e colunas, mas também pode seguir outras formas de segmentação do espaço. Tal divisão visa o estabelecimento da comunicação e identidade entre os elementos da interface e entre as associações de diferentes seções de um mesmo sistema. Um wireframe (figura 3) pode ter alto ou baixo detalhamento, de acordo com a demanda do projeto, e deve estar associado à qualidade de projeto, e não ao engessamento ou cerceamento criativo.

Figura 3: Exemplo de wireframe do site do estúdio 2ADVANCED.
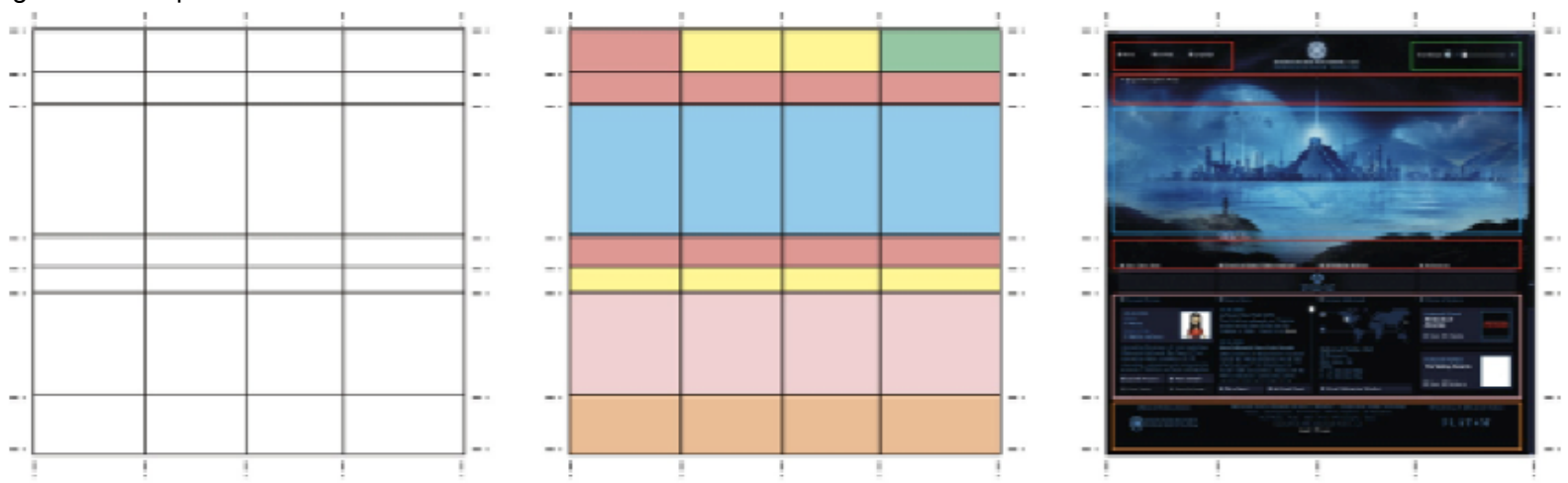

MALHA: sete linhas por quatro colunas.

DEFINIÇÕES DE ÁREAS: menu, controles, conteúdo, destaque, institucional, aplicação da marca.

O wireframe deve ser uma estrutura modular e flexível, podendo ser considerado como o sistema mais elementar de organização, onde objetos visuais e verbais são agentes de comunicação que estabelecem padrões complexos de informação. Neste plano organizam-se os conceitos de linguagem visual, determinando-se pontos focais, margens, espaços, divisões e os próprios limites da interface, facilitando sua legibilidade, seu reconhecimento e a compreensão da mensagem (MOURA, 2003a). 


\subsection{A visualidade da informação}

Após a etapa de estruturação, se encontra a etapa relativa à visualidade da informação. Este é o ponto em que se encontram as informações e os elementos de linguagem que expressam estas informações. Neste momento, o design da informação faz a 'sinalização que torna claros os ambientes e suas divisões, facilitando a compreensão' (RADFAHRER, 2003, p. 125). Apoiado em uma definição conceitual que percorre todo o projeto de design, tanto de maneira funcional quanto formal, é nesta atividade que se dá conceitual e simbolicamente a apresentação das informações por meio da interface.

' Cada ponto de vista, cada modo de organização criará uma nova estrutura. E cada estrutura nova permitirá ver uma nova forma diferente de significado, funcionando como um novo método de classificação a partir do qual o todo pode ser captado e compreendido (WURMAN, 1991, p. 73).'

As interfaces de hipermídias devem permitir ao usuário uma visão panorâmica do conteúdo, além de uma navegação orientada, em toda a massa informacional, de acordo com seus interesses (BONSIEPE, 1997). Com o foco nesta argumentação, o design da informação atua na tradução expressivo-formal do conteúdo, indicando caminhos a serem seguidos no projeto da interface, indicando agrupamentos, ritmos, identidade e abrindo tantas possibilidades quantas forem necessárias ao projetista. O design da informação é responsável pela harmonia que os elementos de uma interface e suas relações virão a ter em sua formação final.

A figura 4 fornece exemplos de um website que demonstra formalmente algumas das características do design da informação citadas até o momento. Tal interface apresenta em suas seções, além de uma identidade visual coesa, uma distribuição de seu conteúdo e uma visualidade que comunica seus conceitos e objetivos, colaborando no acesso e leitura de suas informações.

Na figura 5 podemos evidenciar o design da informação ao confrontarmos suas principais interfaces de acesso. Quando colocamos as cinco interfaces das seções do website citado em fragmentos de áreas equivalentes, formado uma única imagem, podemos perceber as ligações internas ocasionadas por uma identidade única e um discurso expressivo comum, em que o conteúdo é tratado com uma relação visual similar nos espaços da interface. A organização e a identidade são trabalhadas a ponto de se evidenciar que todos os elementos de informação são familiares, relacionados e estão em harmonia, o que pode sugerir a existência do projeto de uma interface matriz para o projeto. 


\section{Infodesıgn}

Figura 4: Seções do site do estúdio 2Advanced.
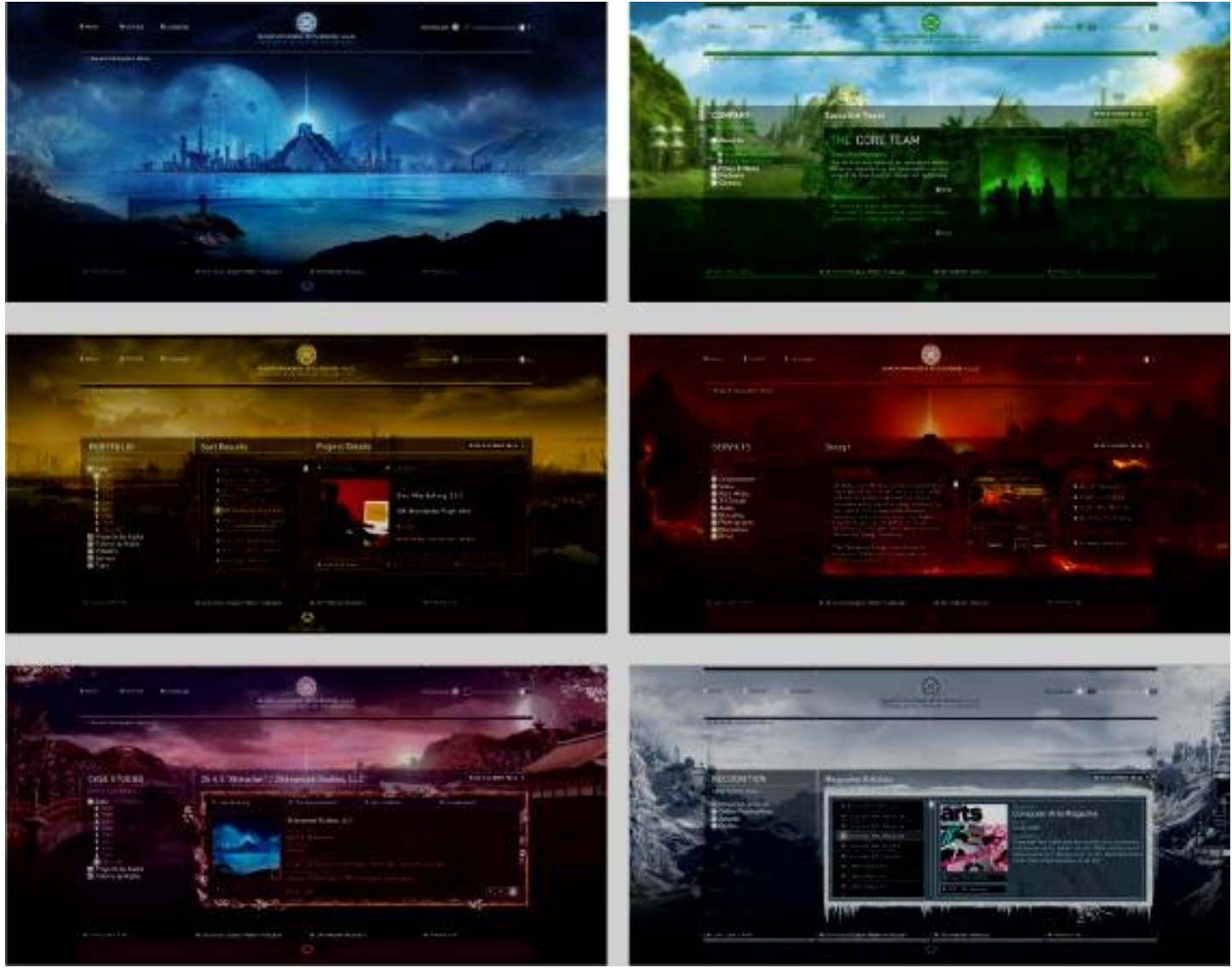

Figura 5: Comparação das seções do site do estúdio 2ADVANCED.

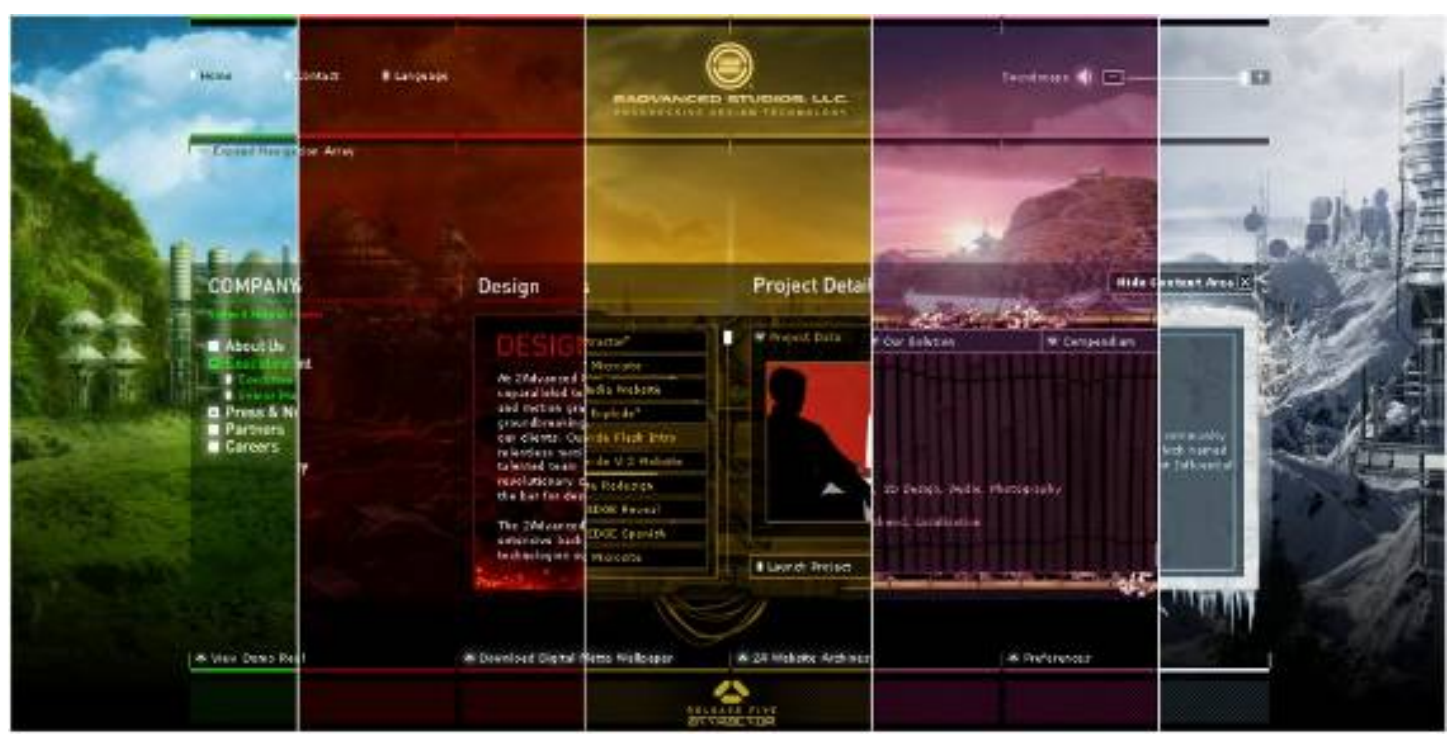

\section{Considerações finais}

Boa aparência e exatidão não implicam necessariamente em informação adequadamente apresentada. Podemos ter fontes precisas e objetivas e nem por isso teremos confiabilidade em seu conteúdo. As pré-concepções são geradoras de um falso sentimento de compreensão, pois não promovem discussão a seu respeito, o que impossibilita a melhoria de sua compreensão (WURMAN, 1991).

Para que um projeto de hipermídia não tenha sua eficiência debilitada ou minimizada, e para que a execução deste projeto não seja limitada, é de extrema importância o papel do design da informação como agente interlocutor na transformação de dados em informação, possibilitando ao designer transpor a simples organização estrutural em comunicação experiencial.

Existem muitas considerações a serem feitas nas crescentes áreas de conhecimento 
relativas às mídias digitais e à hipermídia, assim como acontece com toda nova tecnologia que ainda não tem seu domínio totalmente esgotado e que tem como uma de suas características a mutabilidade. De problemas de nomenclatura a procedimentos, ainda existe muito que se pesquisar e discutir para a consolidação do conhecimento sobre o design da informação neste contexto.

O design da informação tem se mostrado eficiente e necessário no papel de orquestrar o projeto de hipermídia. Ele deve estar inserido desde o apoio na preparação e elaboração do conteúdo de uma hipermídia, passando pela indicação de organização em sua interface e navegação e, por fim, junto ao interator em situação real de uso para validação. Neste universo crescente de informação, será cada vez mais importante o domínio das técnicas, conteúdos e conceitos que facilitem o acesso e a recuperação de informações.

\section{Referências}

2Advanced Studios. Attractor: version 5 (Site do estúdio de design analisado neste trabalho). On-line. Disponível em: <http://www.2advanced.com>. Acessado em: 20 nov. de 2006.

Bonsiepe, G. (1997). Design do Material ao Digital. Florianópolis: FIESC/IEL.

Costa, C. I. (1999). Glossário. In: Lévy, P. Cibercultura. São Paulo: Editora 34, pp. 251-260.

Cybis, W. A (2003). Engenharia de usabilidade: uma abordagem ergonômica. Florianópolis: Labiutil.

Horn, R. E. (1999). Information Design: Emergence of a New Profession. In: Jacobson, R. (Ed). Information design. Cambridge: MIT Press, pp. 15-33.

Lévy, P. (1993). As Tecnologias da Inteligência. São Paulo: Editora 34.

Moura, M. (2003a). O Design de Hipermídia. Tese Doutorado não publicada em Comunicação e Semiótica. Pontifícia Universidade Católica de São Paulo, São Paulo. (2003b). Design de Hipermídia: relações entre cultura, linguagem, transdisciplinaridade e informação. In: Anais do $1^{\circ}$ Congresso de Design da Informação - Selected Readings of the Information Design International Conference 2003. São Paulo: Centro Universitário Senac.

Radfahrer, L. (2003). Design/Web/Design: 2. São Paulo: Market Press.

Rosenfeld, L. \& Morville, P. (2002). Information Architecture for the World Wide Web. Sebastopol: O'Reilly \& Associates.

Ulbricht, V. R. (org.). (2006). Ambientes adaptativos: trilhando novos caminhos para a hipermídia. Rio de Janeiro: Editora Ciência Moderna.

Wurman, R. S. (1991). Ansiedade de informação. São Paulo: Cultura Ed. Associados.

\section{Sobre os autores}

Ravi Passos, Mestrando em Design pela Universidade Anhembi Morumbi. Especialista em Arte, Educação e Tecnologias Contemporâneas pela Universidade de Brasília. Bacharel em Desenho Industrial pela Universidade de Brasília. Professor colaborador do Departamento de Desenho Industrial da Universidade de Brasília. Atua no desenvolvimento de projetos com ênfase em design digital e gráfico.

ravipassos@hotmail.com ; ravipassos@gmail.com

Mônica Moura, Doutora em Comunicação e Semiótica com tese sobre O Design de Hipermídia, PUC- SP. Bacharel em Artes/Arte-Educação pela Belas Artes-SP. Artista Visual. DesignEducadora. Professora e Pesquisadora do Mestrado em Design / Pós-Graduação Stricto Sensu e Diretora do Centro de Pesquisa em Design e do Campus Morumbi da Universidade Anhembi Morumbi.

mônica@anhembi.br 